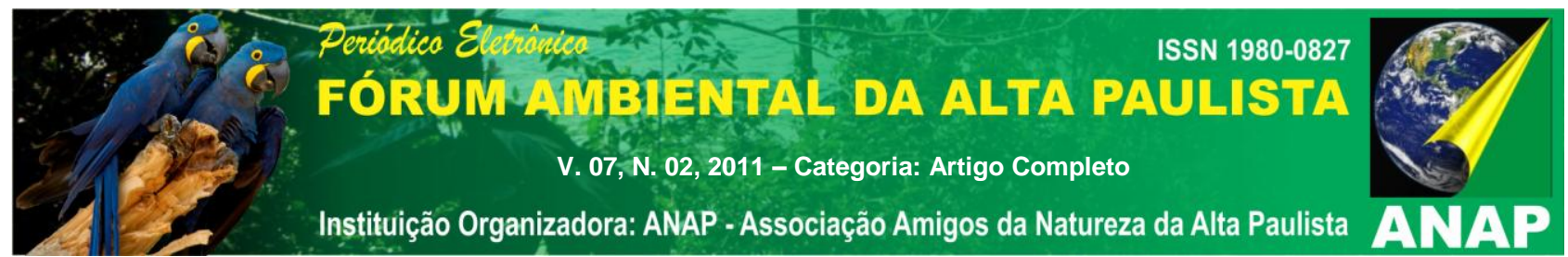

\title{
ANÁLISE AMBIENTAL DA SUB BACIA BOA ESPERANÇA, NO MUNICÍPIO DE BRASILÂNDIA - MS - BRASIL
}

\section{Camila Balista Garbeline ${ }^{1}$}

\section{Wallace de Oliveira ${ }^{2}$}

Resumo: A bacia hidrográfica é identificada como um sistema que vem ao longo da história sofrendo cada vez maiores modificações no seu ambiente seja por processos da própria evolução natural, mas também é afetada por maneiras incorretas de uso e ocupação do solo. O presente trabalho tem o objetivo de através do estudo da sub bacia Ribeirão Boa Esperança, localizado no município de Brasilândia-MS, obter informações da vulnerabilidade do solo, e do uso e ocupação do solo, possibilitando elaborar um planejamento ambiental. Foram utilizadas a carta topográfica de 1972 e imagens de satélite Landsat TM+ dos diferentes anos 2000 e 2011. Nos anos estudados o uso e ocupação do solo para cultura eram poucos, mas em 2011 essa classe aumentou, e percebe-se que o uso do solo é destinado principalmente para pastagem. Para tanto se sugere para não degradar o ambiente, que se utilizem sistemas de manejo adequado.

Palavras-chave: Imagens de satélite. Sensoriamento remoto. Sub bacia

\section{INTRODUÇÃO}

O ambiente pode ser afetado ou descrito por aspectos físicos, químicos e biológicos, tanto naturais como construídos pelo homem. Mas devido ao aumento das degradações e impactos causados pelo homem, fez surgir à preocupação com a água, com a poluição e com os impactos sociais, que foram mudanças ocorridas e sendo somadas ao longo da história até chegar num patamar de preocupação com as questões ambientais. Dessas preocupações surgi o conceito de planejamento (uma idéia um pouco utópica se for pensar em planejamento totalmente sustentável) voltado para a conservação ambiental.

\footnotetext{
${ }^{1}$ Acadêmica do curso de Geografia-Bacharelado da UFMS. camila-garbeline@hotmail.com

${ }^{2}$ Professor da UFMS, Departamento de Ciências Humanas. wallace@cptl.ufms.br
} 


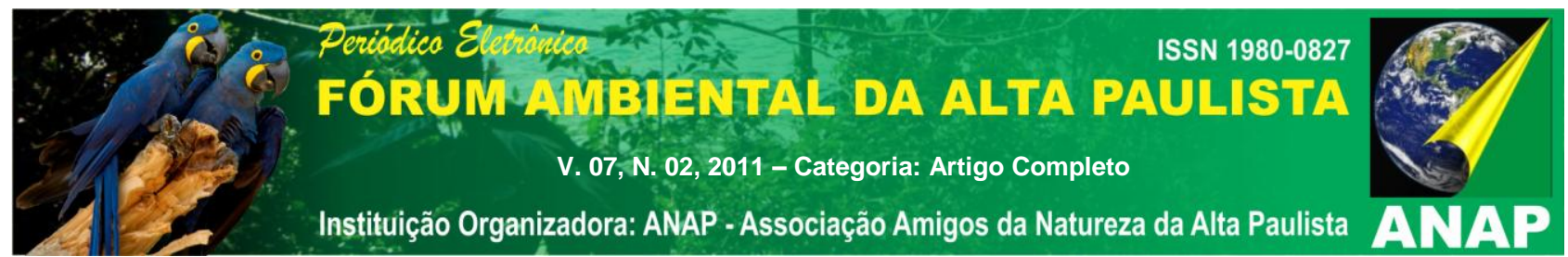

Para um bom planejamento deve-se buscar antecipar as necessidades para as futuras gerações de maneira a garantir o equilíbrio do meio ambiente. Por isso é importante conhecer o espaço, tempo (processo de transformação), sociedade e a natureza, assim podendo elaborar diagnósticos e estabelecer diretrizes para diminuir os efeitos negativos no ambiente, ou até mesmo preveni-los.

Com um planejamento ambiental se tem possibilidades de recuperar e analisar possíveis áreas degradadas. Através do estudo de uso e ocupação do solo das unidades das paisagens, podem-se elaborar diagnósticos quando é percebido o uso inapropriado dos recursos naturais.

Planejamento para Floriano (2004, p.08):

processo de organização do trabalho de uma equipe para consecução de objetivos comuns, de forma que os impactos resultantes que afetam negativamente o ambiente em que vivemos sejam minimizados e que os impactos positivos sejam maximizados.

Para se certificar sobre o processo de transformação do ambiente estão sendo utilizado nos últimos anos de acordo com Paranhos (2008), geotecnologias, como o SIG (Sistema de Informação Geográfica), Sensoriamento Remoto que utilizam imagens de satélite, a qual se tem tornado ferramentas imprescindíveis e que estão cada vez mais disponíveis a todos os tipos de usuários, tais imagens retratam o ambiente e sua transformação, os impactos causados por fenômenos naturais e antrópicos. São técnicas mais avançadas que ajudam na obtenção dos resultados a serem adquiridos.

Nos anos comparados é mostrada uma modificação no ambiente, devido ao aumento da degradação, é importante um gerenciamento e planejamento ambiental. Para um planejamento ambiental é preciso ter um diagnóstico e prognóstico para poder formular diretrizes.

Devido a essas degradações foi elaborada uma importante lei federal para conservação da natureza em território nacional é o Código Florestal Brasileiro (que vem a estar em processo de modificação na lei).

Área de Preservação Permanente foi definida na Medida Provisória nº. 2.166-67, de 24.08.2001, como: 


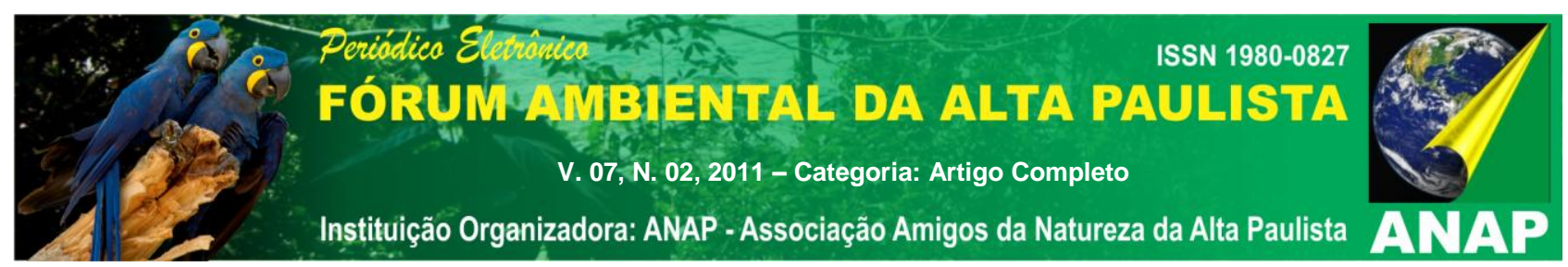

área protegida nos termos dos artigos $2^{\circ}$ e $3^{\circ}$ desta Lei, coberta ou não por vegetação nativa, com a função ambiental de preservar os recursos hídricos, a paisagem, a estabilidade geológica, a biodiversidade, o fluxo gênico de fauna e flora, proteger o solo e assegurar o bem-estar das populações humanas. (FELISBERTO, 2009, p. 121)

O Código Florestal considerou ao redor das lagoas, lagos ou reservatórios de água naturais ou artificiais área de preservação permanente (FELISBERTO, 2009, p.121)

O presente trabalho tem o objetivo de através do estudo da sub bacia Ribeirão Boa Esperança, Brasilândia-MS, obter informações do uso e ocupação do solo, e da vulnerabilidade do solo, possibilitando mais tarde elaborar um planejamento ambiental.

\section{DESENVOLVIMENTO}

O município de Brasilândia se localiza na porção leste do Estado de Mato Grosso do Sul, região Centro-Sul do Brasil, possuindo uma área de $5.806 .89 \mathrm{~km}^{2}$, com

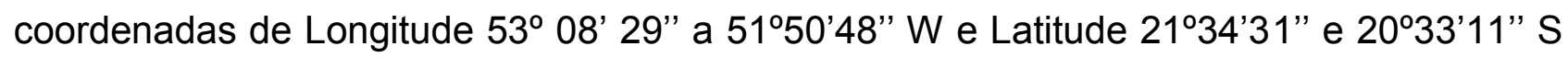
(IBGE, 2007) (Figura 1)

Figura 1 - Localização da sub bacia Ribeirão Boa Esperança, município de Brasilândia (MS) 


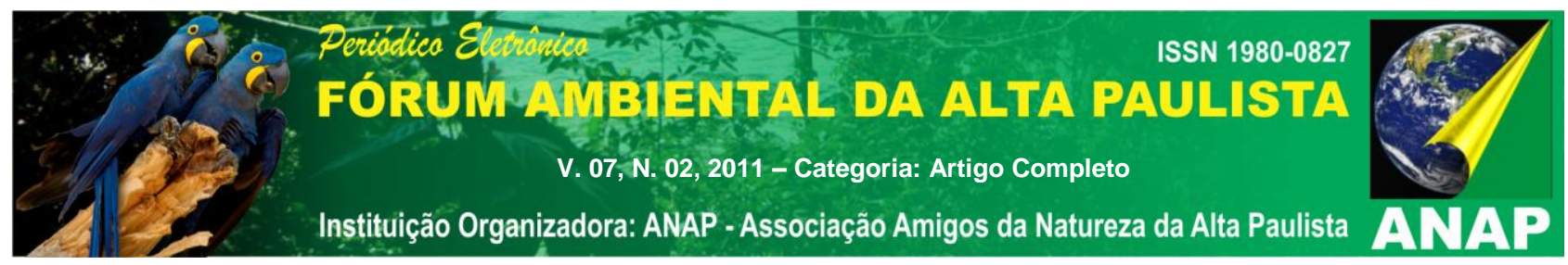

\section{Localização da Sub Bacia Ribeirão Boa Esperança}

W $52^{\circ} 19^{\prime} 59^{\prime \prime}$

$S 21^{\circ} 11^{\prime} 49^{\prime}$

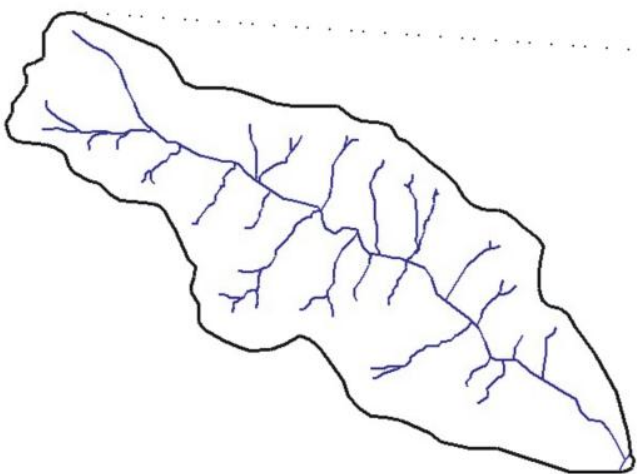

$\mathrm{S} 21^{\circ} 26^{\prime} 23$

W $52^{\circ} 00^{\prime} 25^{\prime \prime}$
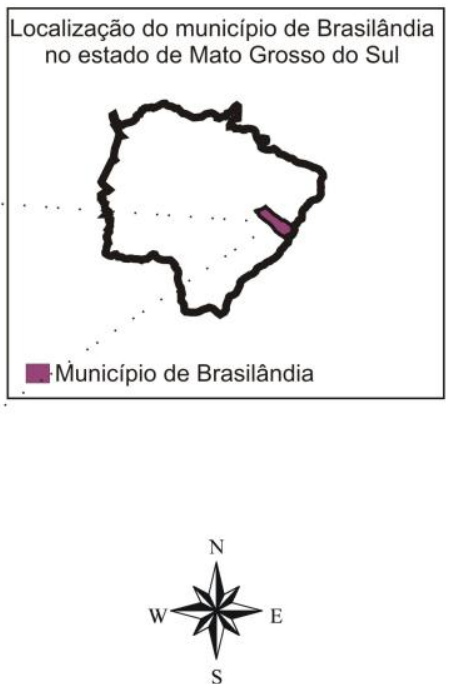

UFMS - Universidade Federal do Mato Grosso do Sul

Fonte: Banco de Dados do Brasil, INPE 2008

Edição: Camila Balista Garbeline

Datum WGS84, Projeção UTM, Zona 22s

Fonte: Banco de Dados do Brasil, INPE 2008 Edição: Camila Balista Garbeline

\subsection{USO E OCUPAÇÃO DO SOLO}

Os dados adquiridos no SIG possibilitaram executar o contraste, e classificar a imagem, a partir desses dados podem-se comparar as imagens pelo uso e ocupação do solo, como mostrado na Figura 2. Por fim quantificar uma porcentagem de cada classe para os anos de 2000 e 2011 (Tabela 1). As porcentagens mostradas na tabela não chegam a um total de $100 \%$, pois o trabalho é feito com um software SIG, que como foi trabalhado por classificação por atributos de região não se obteve uma boa diferenciação das classes, surgindo assim pequenos erros.

Optamos neste estudo por identificar e quantificar seis categorias para análise, são elas: Corpos Aquosos, Cultura, Pastagem, Vegetação Arbórea, Vegetação Rala e Solo $\mathrm{Nu}$. Na Tabela 1 está descrito cada classe do uso e ocupação do solo. 


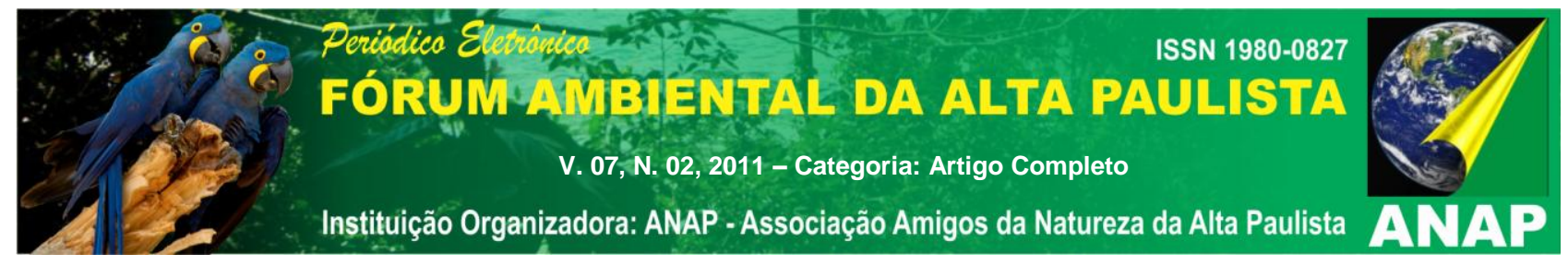

Figura 2 - Uso e ocupação do solo na sub bacia Ribeirão Boa Esperança.

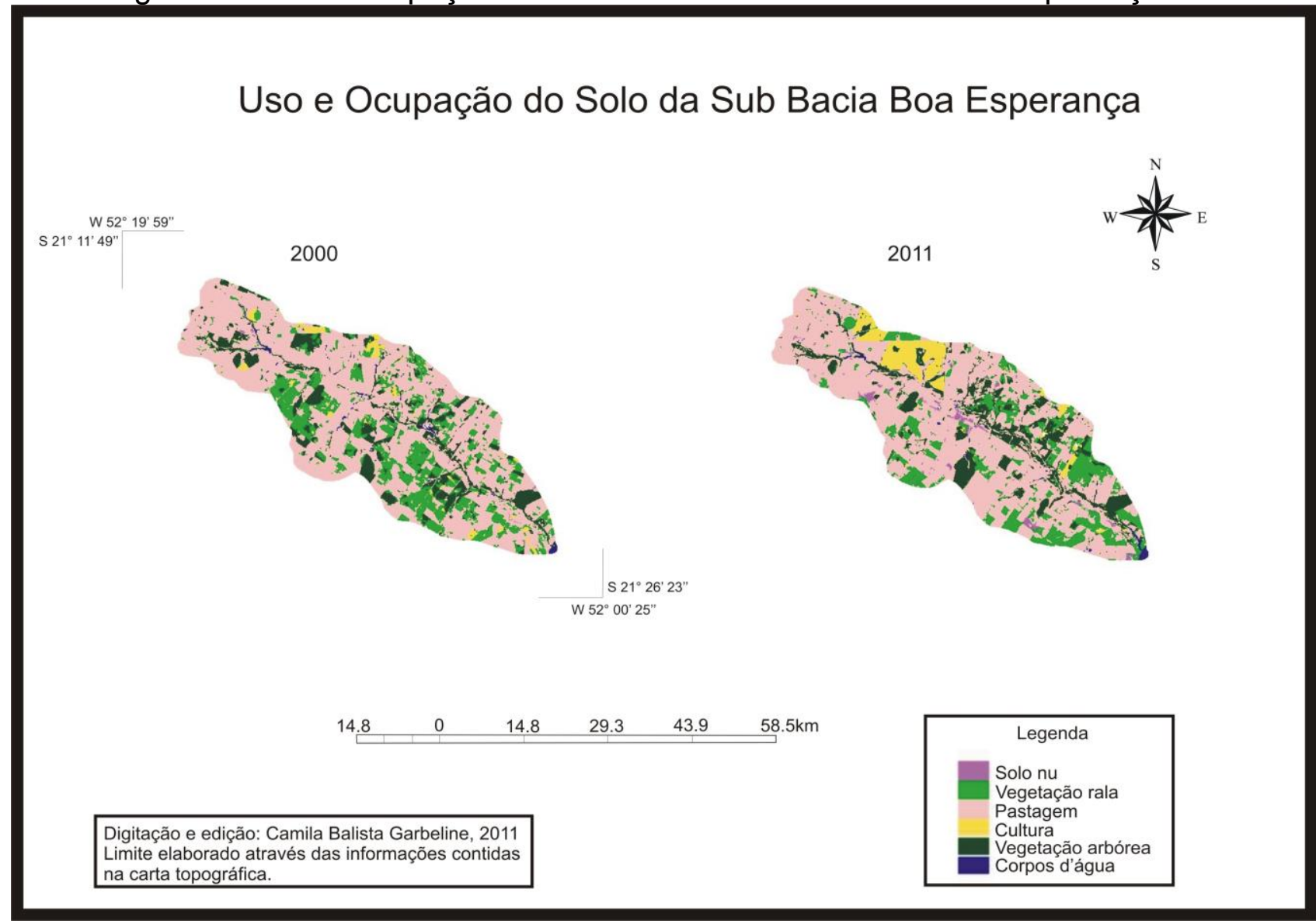

Fonte: Spring 4.3.3 (SIG) Edição: Camila Balista Garbeline

Tabela 1 - Porcentagem das classes de uso e ocupação do solo na sub bacia Ribeirão Boa Esperança.

\begin{tabular}{|lrr|}
\hline Ribeirão Boa Esperança & Ano 2000 & Ano 2011 \\
\hline Classes/Percentual & $\%$ & 0,56 \\
Corpos Aquosos & 0,64 & 6,18 \\
Cultura & 2,23 & 62,56 \\
Pastagem & 64,59 & 13,67 \\
Vegetação Arbórea & 12,99 & 15,54 \\
Vegetação Rala & 19,43 & 1,46 \\
Solo Nu & 0,09 & 99,97 \\
\hline
\end{tabular}

Fonte: Spring 4.3.3 (SIG) Organizado por Camila Balista Garbeline (2011) 


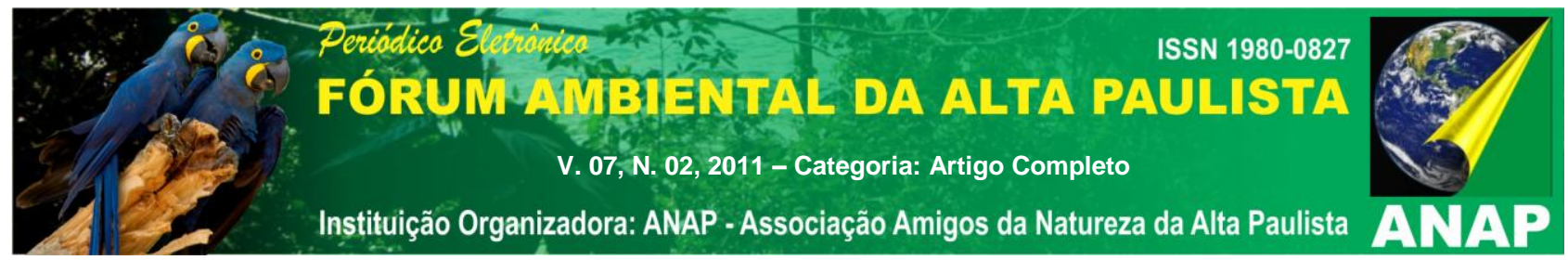

Observa-se que os corpos d'água nos dois anos estudados aparecem em pequena quantidade, mas que diminuem do ano 2000 para 2011, passando de $0,64 \%$ para $0,56 \%$ respectivamente. Essa diminuição pode ser devido ao assoreamento de um ou mais canais.

A vegetação arbórea com o passar dos anos analisados apresentou um pequeno crescimento, em 2000 estava com 12,99\% e passou para 13,67\% em 2011. Esse aumento pode ser devido a alguma área recuperada.

A vegetação rala teve uma diminuição, em 2000 estava ocupando uma área de 19,43\%, e no ano de 2011 passou a ocupar 15,54\%. Pode se explicar essa diminuição a uma maior quantidade de plantio de cultura, ou ao aumento do solo nu.

Pastagem mostrou ser predominante na área, em 2000 apresentou 64,59\% de toda a área da bacia, e em 2011 decaiu para 62,56\%, mesmo com essa diminuição não deixou de ser predominante na área. Essa modificação pode ser explicada ao aumento das culturas permanentes e temporárias.

A Cultura teve um aumento do ano de 2000 para 2011, passando de 2,23\% para $6,18 \%$ de ocupação respectivamente. Analisando os dados percebe-se que a cultura vem crescendo como atividade econômica devida a instalação da fábrica de Celulose no município de Três Lagoas.

Para o autor (MARION, 2000 apud ZUCCOLOTTO; NOSSA.) o cultivo do eucalipto pode ser considerado como cultura temporária ou permanente, isto é vinculado ao modo de produção. No entanto, esta cultura leva sete anos em média para ser formada. No conceito de cultura temporária o período de vida útil é curto, menor que um ano e a cada safra exige-se um novo plantio.

A classe de solo nu, que são áreas de resultado do pisoteio do gado, áreas muito degradadas que não tem um fim econômico de uso. Em 2000 representava 0,09\%, aumentando em 2011 para 1,46\%.

\subsection{SOLOS}




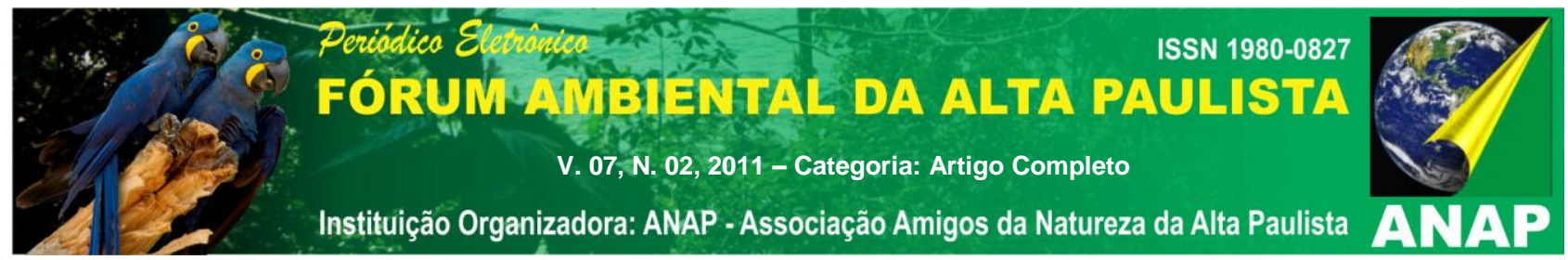

Segundo Lepsch (2002) a definição de solo é ampla, abrange definições de vários tipos, para alguns, solo é sinônimo de qualquer parte da superfície da Terra. Por exemplo, os Geólogos podem entendê-lo como parte de uma seqüência de eventos geológicos no chamado "ciclo geológico". Para o pedólogo o solo é a coleção de corpos naturais dinâmicos, contém matéria viva, e é resultante da ação do clima e da biosfera sobre a rocha, a transformação do solo é influenciada pelo tipo de relevo.

Os solos são de diferentes tipos, e são controlados por cinco importantes fatores, são eles: clima, tempo, relevo, organismos e material de origem. De acordo com Lepsch (2002) podemos dividir esses fatores de formação do solo em dói tipos, os "fatores ativos" e os "fatores passivos". O clima e os organismos são os "fatores ativos" porque, agem diretamente sobre o material de origem.

O intemperismo é o fenômeno responsável pela formação do material que da formação ao solo. De acordo com Crepani et. Al. (2001) o intemperismo pode ser definido como alteração física e química. No intemperismo físico predominam os processos de desintegração, já no intemperismo químico prevalecem os processos de decomposição.

Segundo Lepsch (2002) o clima é o principal fator que influencia o intemperismo, e seus principais elementos são: temperatura e umidade, eles regulam o tipo e a intensidade de intemperismo das rochas.

Para Crepani et. Al. (2001) o clima através da precipitação pluviométrica e da temperatura de uma região influencia diretamente no intemperismo, e indiretamente através dos tipos de vegetação que cobrem a paisagem.

De acordo com Lepsch (2002) os fatores que afetam a erosão no solo pela água são quatro os principais: clima da região, tipo de solo, declividade do terreno e o manejo do solo.

O Clima afeta na erosão devido a quantidade e a intensidade das chuvas. Quando a chuva é de forma de pequenas gotas e caem durante um período de várias horas, tem mais tempo para serem absorvidas pelo solo, assim não causando grandes estragos. Mas se essa quantidade de chuva cair rapidamente e principalmente se o terreno estiver sem uma vegetação adequada, em alguns minutos formará grandes enxurradas e poderá provocar grandes erosões. (LEPSCH, 2002, p.157)

Certos solos são mais suscetíveis a erosão do que outros dependendo da sua natureza, de acordo com suas características físicas, como textura, permeabilidade e 


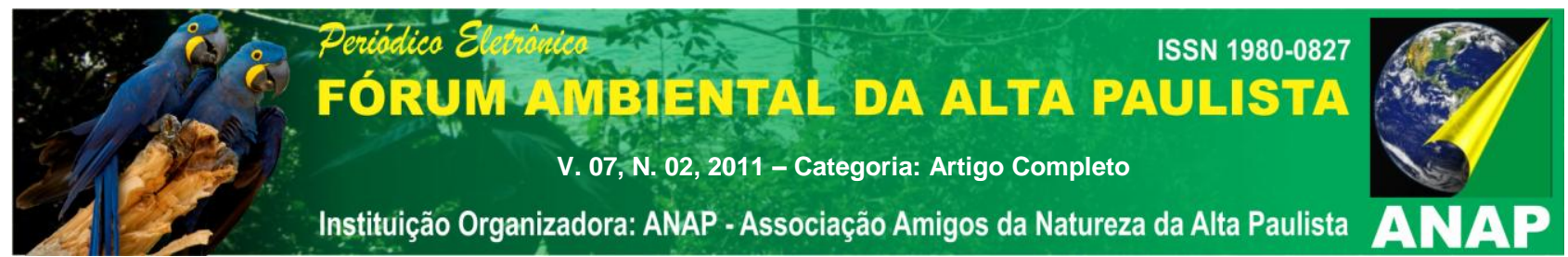

profundidade. Mas o que também ajuda os solos serem menos sujeitos a erosão é um bom desenvolvimento das plantas. . (LEPSCH, 2002, p.158)

A declividade influencia na concentração, velocidade e dispersão da enxurrada, decidindo um maior ou menor arrastamento das partículas do solo. (LEPSCH, 2002, p.158)

O manejo do solo tem ligação com a cobertura vegetal, solos completamente cobertos por vegetação têm condições de resistir à erosão e ao impacto da chuva no solo. (LEPSCH, 2002, p.158)

Segundo Crepani et. Al. (2001) os solos são produtos do balanço entre a morfogênese e a pedogênese indicando se prevalecem os processos erosivos da morfogênese, ou se prevalecem os processos que geram solos bem desenvolvidos (pedogênese).

A unidade da paisagem que é considerada estável para Crepani et. Al. (2001), quando nela favorecem os processos de pedogênese, quer dizer que no ambiente se encontram solos bastante desenvolvidos, intemperizados e envelhecidos.

Agora aquela paisagem que é considerada vulnerável para Crepani et. Al. (2001), quando prevalecem os processos de morfogênese, que são processos modificadores do relevo, que podem incluir a erosão na formação e desenvolvimento do solo.

Podemos ver na tabela 2 os valores de vulnerabilidade e suas características de acordo com a proposta de Crepani et. Al. (2001).

Tabela 2 - Valores de vulnerabilidade e classificação dos solos

\begin{tabular}{|c|c|c|c|}
\hline Solo & Unidade & $\begin{array}{l}\text { Vulnera- } \\
\text { bilidade. }\end{array}$ & Características \\
\hline $\begin{array}{l}\text { Latossolo } \\
\text { Vermelho }\end{array}$ & Estável & 1 & $\begin{array}{l}\text { Solos bem desenvolvidos, com grande } \\
\text { profundidade e porosidade, sendo, portanto } \\
\text { considerado os solos cujos materiais são os } \\
\text { mais decompostos. A principal limitação ao } \\
\text { uso agrícola é a baixa fertilidade natural. }\end{array}$ \\
\hline Planossolos & Intermediária & 2 & $\begin{array}{l}\text { A diferença de textura entre os horizontes A } \\
\text { e B (pelo acumulo de argila no horizonte B) } \\
\text { dificulta a infiltração da água, o que favorece } \\
\text { o processo de erosão. }\end{array}$ \\
\hline $\begin{array}{l}\text { Neossolos } \\
\text { Quartzarênicos }\end{array}$ & Vulnerável & 3 & $\begin{array}{l}\text { Solos jovens e pouco desenvolvidos, sua } \\
\text { característica principal é a pouco evolução }\end{array}$ \\
\hline
\end{tabular}




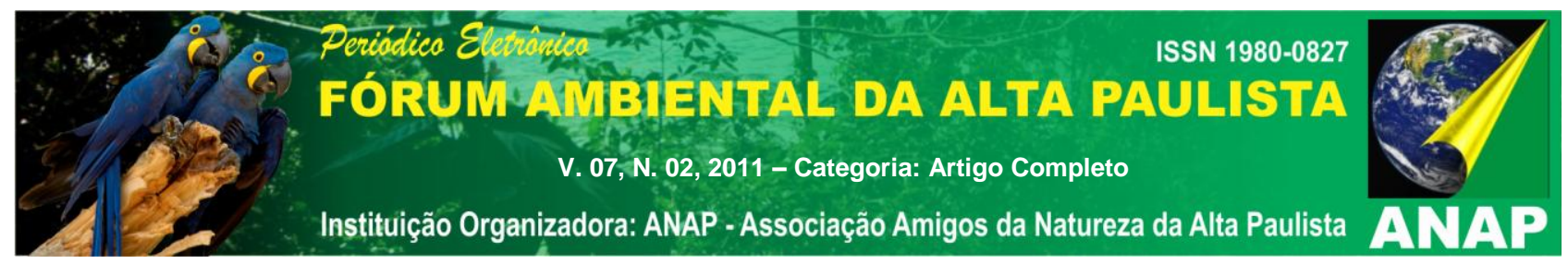

\begin{tabular}{|lll|}
\hline & & $\begin{array}{l}\text { dos perfis do solo. E podem estar situados em } \\
\text { lugares de alta declividade, nos quais a } \\
\text { velocidade da erosão é igual ou maior que a } \\
\text { velocidade de transformação da rocha em } \\
\text { solo. }\end{array}$ \\
Nitossolo & A diferença de textura entre os horizontes A \\
Vermelho & Intermediária & $2 \quad \begin{array}{l}\text { e B (pelo acumulo de argila no horizonte B) } \\
\text { dificulta a infiltração da água, o que favorece } \\
\text { o processo de erosão. }\end{array}$ \\
\hline
\end{tabular}

Fonte: Crepani et al (2001) Organizado e Modificado por Camila Balista Garbeline

$\mathrm{Na}$ tabela 3 os tipos de solos e suas características encontrados na sub bacia Ribeirão Boa Esperança.

Tabela 3 - Tipos de solos da bub bacia Ribeirão Boa Esperança.

Tipo de Solos Características

\begin{tabular}{|ll} 
Latossolo & $\begin{array}{l}\text { São ácidos e pobres em nutrientes. Podem ser } \\
\text { utilizados para a agricultura intensiva, desde que se } \\
\text { faça a neutralização da acidez. }\end{array}$ \\
Planossolos & $\begin{array}{l}\text { Quantidade de argila consideravelmente mais } \\
\text { elevada, baixa permeabilidade e baixos teores de } \\
\text { matéria orgânica. }\end{array}$ \\
Neossolos Quartzarênicos & $\begin{array}{l}\text { Textura arenosa e muito resistente ao intemperismo. } \\
\text { Nitossolos }\end{array}$ \\
Mais conhecido como "terra roxa", em condições \\
naturais são os melhores para agricultura intensiva \\
desde que não se situe em áreas com relevo de \\
declives muito fortes, quando em declives forte são \\
suscetíveis à erosão hídrica.
\end{tabular}

Fonte: Lepsch (2002) Organizado e Modificado por Camila Balista Garbeline

\section{CONCLUSÃO}

Os mapas são de grande importância para obtenção de dados e variáveis para análise ambiental. Os resultados adquiridos nas imagens de satélite através de emprego do Spring ${ }^{\circledR} 4.3 .3$, permitiu interpretar e relacionar os dados, demonstrando as mudanças 


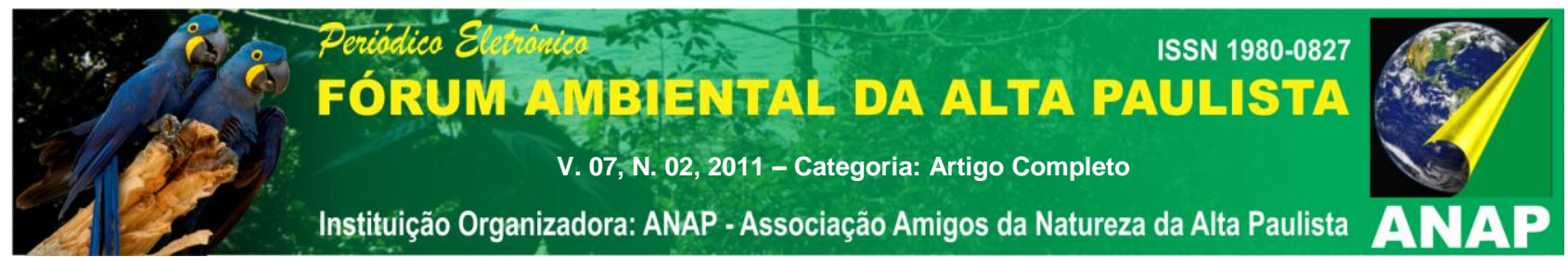

ocorridas no ambiente, apresentando as principais transformações e seus efeitos que refletem diretamente nas estruturas naturais.

Toda área tem seu grau de vulnerabilidade, possui fatores que propiciam aos processos de erosão do solo, mas na área estudada percebe-se que a ação antrópica influencia nos processos de erosão do solo por falta de práticas conservacionistas.

Analisando o uso e ocupação do solo, conclui-se que houve mudanças ocorridas no ambiente por processos naturais, ou/e por degradações antrópicas. Com os dados obtidos pode-se afirmar que houve um incremento da cultura (lavoura) na área da bacia. Não foram diferenciadas as culturas de cana e eucalipto, mas pressupõem este acréscimo seja eucalipto devido à economia local e regional necessitar dessa matéria prima, pois a região está se especializando no setor celulose/papel.

Já o uso pastoril sempre esteve presente na região, devido às características econômicas local/regional. Nos dois anos estudados sempre teve uma maior área se comparada com as outras classes, chegando a ocupar mais da metade da sub bacia.

Como a maior parte do uso da terra é para pastagem e esta se desenvolvendo culturas, sugere-se para não degradar o ambiente, que se utilizem sistemas de manejo como curva de nível, não identificadas nas imagens, técnicas de conservação do solo, evitando assim o escoamento superficial da água, adiando o surgimento de processos erosivos como ravinas, voçorocas, empobrecimento do solo, e outras degradações ambientais. Mas todo esse processo de cuidado e atenção com o ambiente deve ser adotado tanto pelos órgãos públicos e como também pelo setor privado, para garantir um uso mais adequado dos recursos naturais respeitando suas características e limitações, explorando sim economicamente, porém com a menor degradação possível ao ambiente.

\section{REFERÊNCIAS}

CREPANI, E.; MEDEIROS, J.S.de; HERNANDEZ FILHO,P.; FLORENZANO,T.G.; DUARTE,V.; BARBOSA,C.C.F. Sensoriamento Remoto e Geoprocessamento Aplicados ao Zoneamento Ecológico-Econômico e ao Ordenamento Territorial. São José dos Campos: INPE, 2001.

CREPANI, E., MEDEIROS, J.S., AZEVEDO, L.G. de., HERNANDEZ FILHO, P., FLORENZANO, T.G., DUARTE, V. Curso De Sensoriamento Remoto Aplicado Ao Zoneamento Ecológico-Econômico. São José dos Campos: INPE, 1996. 


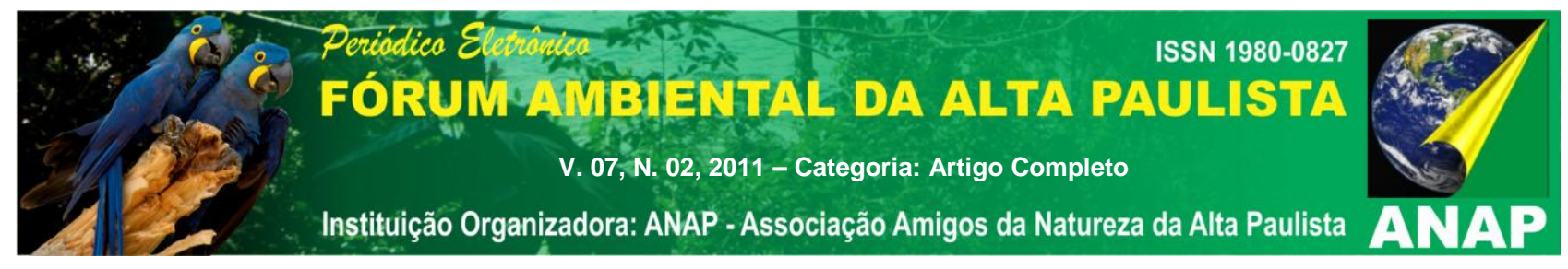

FLORIANO, E. P. Planejamento Ambiental. Rio Grande do Sul: Santa Rosa, 2004.

LEPSCH, I.F. Formação e Conservação dos Solos. Sao Paulo: Oficina de Textos, 2002.

SANTOS, D.G. dos e NUCCI, J.C. Paisagens Geográficas: Um tributo a Felisberto Cavalheiro. Campo Mourão, Editora da FECILCAM, 2009.

ZUCCOLOTTO, R.; NOSSA, V. Contabilização de ativos com crescimento vegetativo: o caso da Aracruz celulose S. A.

Disponível em: <http://www.fucape.br/_admin/upload/centro_pesquisa/13592.pdf>. Acesso em: 12/08/02010 